\title{
SIMILARITY CRITERIA OF EHF PHYSICAL MODEL OF LONG DISTANCE TRANSMISSION LINE WITH PLATE PHASES
}

\author{
M. HAMED \\ Electrical Dept., Faculty of Engineering, Suez Canal University, Port Said, Egypt
}

(Received July 16, 1986)

Carson's equations for computation of frequency dependent parameters of overhead transmission line are modified. The earth is considered to be homogenous. The optimal required number of terms of Carson's series for applications on computer is determined. Accurate mathematical expressions for resistance and inductance of overhead transmission lines are obtained.

Different arrangements of conductors for double circuit transmission lines are studied. The mutual inductance and potential coefficient (mutual capacitance) of such arrangements are computed. Double voltage class type double circuit transmission lines are suggested. The plate type double circuit lines are proposed for power transmission over long distances.

This paper presents a mathematical analysis in order to determine the coefficients of similarity criteria of EHF physical model for the given long distance transmission line. The integral analogue method and PI-theorem are used. The independent parameters of EHF physical model are formulated. The scales of four independent parameters of the designed EHF physical model are obtained.

\section{INTRODUCTION}

Recently, large blocks of powers are needed to be transmitted over long distances. Hence, the long distance transmission line should be applied. The power transmission may be realised using either controlled or coaxial lines ${ }^{1,2}$ as well as the problem of power transmissions over long distances as discussed previously ${ }^{3}$. It is known that many difficulties will occur if long UHV transmission lines are introduced. The study of electrical performance of such type of lines becomes an interesting subject which may be acheived by physical models ${ }^{4}$. 


\section{FREQUENCY DEPENDENT PARAMETERS}

The earth return effect on long distance lines must be included in the mathematical analysis of transmission line parameters. The effect of a homogenous earth on overhead wires has been studied before ${ }^{5}$, when the line parameters such as resistance $R$ and inductance $L$ become frequency dependent. The resistance and inductance of a conductor (Fig. 1) may be expressed as ${ }^{5}$ :

$$
\begin{array}{ll}
\mathrm{R}=\mathrm{R}_{\mathrm{o}}+4 \omega 10^{-4} \mathrm{Y} & \mathrm{ohms} / \mathrm{km} \\
\mathrm{L}=0.4 \mathrm{Q} & \mathrm{mH} / \mathrm{km}
\end{array}
$$

where $\omega$ and $R_{o}$ are angular frequency and d.c. resistance of a conductor, respectively. The geometrical angle $\beta$ and distance $\mathrm{r}$ may be defined by

$$
\begin{aligned}
\beta & =\arctan \left(\mathrm{h}_{\mathrm{ab}} / \mathrm{y}_{\mathrm{ab}}\right) \\
\mathrm{r}^{2} & =\mathrm{h}_{\mathrm{ab}}^{2}+\mathrm{y}_{\mathrm{ab}}^{2} \\
\mathrm{y}_{\mathrm{ab}} & =2 \mathrm{Z}_{\mathrm{ab}} \sqrt{ } \pi \omega \mathrm{d} \\
\mathrm{h}_{\mathrm{ab}} & =2 \mathrm{X}_{\mathrm{ab}} \sqrt{ } \pi \omega \mathrm{d}
\end{aligned}
$$

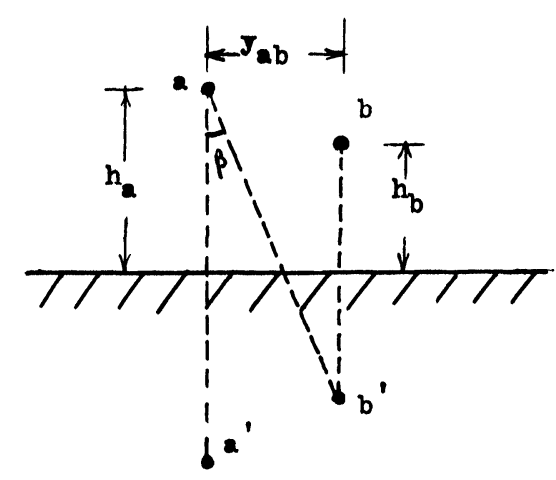

FIGURE 1 Arrangement of conductors with mirror effect. 
The coefficients $X_{a b}$ and $Z_{a b}$ are horizontal and vertical distances between conductor $a$ and image $b^{\prime}$ (Fig. 1). The conductivity of ground is represented by $d$.

The functions $\mathrm{Y}$ and $\mathrm{Q}$ can be tailored as;

$$
\begin{aligned}
& \mathrm{Y}=\frac{\pi}{8}+\frac{\mathrm{S}_{1}}{2}\left(\frac{5}{4}+\log \frac{2}{\gamma \mathrm{r}}\right)+\frac{\beta}{2} \mathrm{~S}_{2}-\frac{\pi}{8} \mathrm{~S}_{3}-\frac{\mathrm{S}_{5}}{\sqrt{ } 2}+\frac{\mathrm{S}_{6}}{\sqrt{ } 2} \\
& \mathrm{Q}=\frac{1}{4}+\frac{1}{2} \log \frac{2}{\gamma \mathrm{r}}-\frac{\pi}{8} \mathrm{~S}_{1}-\frac{\mathrm{S}_{3}}{2}\left(\frac{5}{3}+\log \frac{2}{\gamma \mathrm{r}}\right)-\frac{\beta \mathrm{S}_{4}}{2}+\frac{\mathrm{S}_{5}+\mathrm{S}_{6}}{\sqrt{ } 2}
\end{aligned}
$$

where $\log \gamma$ is Euler's constant. The functions $\mathrm{S}_{1}, \ldots, \mathrm{S}_{6}$ are infinite series and they may be written as follows:

$$
\begin{aligned}
\mathrm{S}_{1}+\mathrm{jS}_{2} & =\frac{(\mathrm{r} / 2)^{2}}{1 ! 2 !}(\cos 2 \beta+\mathrm{j} \sin 2 \beta)-\frac{(\mathrm{r} / 2)^{6}}{3 ! 4 !}(\cos 6 \beta+\mathrm{j} \sin 6 \beta)+\ldots \\
\mathrm{S}_{3}+\mathrm{jS}_{4} & =\frac{(\mathrm{r} / 2)^{4}}{2 ! 3 !}(\cos 4 \beta+\mathrm{j} \sin 4 \beta)-\frac{(\mathrm{r} / 2)^{8}}{4 ! 5 !}(\cos 8 \beta+\mathrm{j} \sin 8 \beta)+\ldots \\
\mathrm{S}_{5} & =\frac{\mathrm{r} \cos \beta}{3} \frac{\mathrm{r}^{5} \cos 5 \beta}{3^{2} 5^{2} 7}+\frac{\mathrm{r}^{9} \cos 9 \beta}{3^{2} 5^{2} 7^{2} 9^{2} 11}-\ldots \\
\mathrm{S}_{6} & =\frac{\mathrm{r}^{3} \cos 3 \beta}{3^{2} 5}-\frac{\mathrm{r}^{7} \cos 7 \beta}{3^{2} 5^{2} 7^{2} 9}+\frac{\mathrm{r}^{11} \cos 11 \beta}{3^{2} 5^{2} 7^{2} 9^{2} 11^{2} 13}-\ldots
\end{aligned}
$$

Although expressions (3) are appeared to be complex, they rapidly converge. Application of the series on a computer creates a computer error "Order Disappearance". In this case the results are not real, and this error should be eliminated so that accurate results must be deduced. For this purpose the maximum permissible number of terms can be obtained. Thus, the computer program of reference ${ }^{6}$ must be modified for use.

Results prove that the maximum permissible number of series terms is five. The optimal number of terms must be determined. For this purpose, two, three, four and five terms are considered. The calculations, repeated for each case, show that only two terms of the series is an optimal number for computation of line parameters in 
order to reduce the computational time. Therefore, the optimal expressions for resistance and inductance may be simplified in the final form:

$$
\begin{aligned}
\mathrm{R}= & \mathrm{R}_{\mathrm{o}}+4 \omega 10^{-4}\left(0.39-\frac{\mathrm{r}^{4} \cos 4 \beta}{489.2}+\frac{\mathrm{r}^{8} \cos 8 \beta}{18.810^{5}}\right) \\
\mathrm{L}= & 0.4\left(\log (2.5 / \sqrt{ } \mathrm{r})+\mathrm{r} \cos \beta / 4.24-\mathrm{r}^{2} \cos 2 \beta / 20.38\right. \\
& +\mathrm{r}^{3} \cos 3 \beta / 63.82-\left(\cos 4 \beta \log \left(2(10)^{1.66} / \gamma \mathrm{r}\right)+\beta \sin 4 \beta\right) \mathrm{r}^{4} / 384 \\
& +\mathrm{r}^{5} \cos 5 \beta /\left(2.2310^{3}\right)+\mathrm{r}^{6} 10^{-4} \cos 6 \beta / 2.3-\mathrm{r}^{7} 10^{-5} \cos 7 \beta / 1.4 \\
& \left.+\left(\cos 8 \beta \log \left(2(10)^{2.18} / \gamma \mathrm{r}\right)-\beta \sin 8 \beta\right) \mathrm{r}^{8} 10^{-6} / 1.5\right)
\end{aligned}
$$

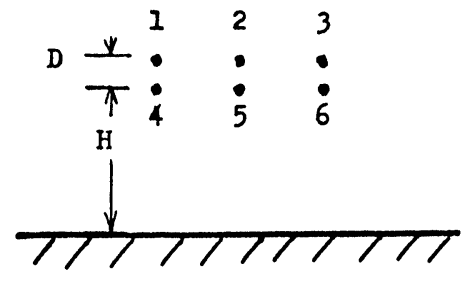

(a) vertical arrangement

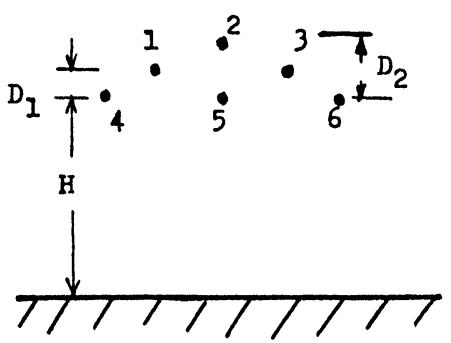

(c) compact arrangement

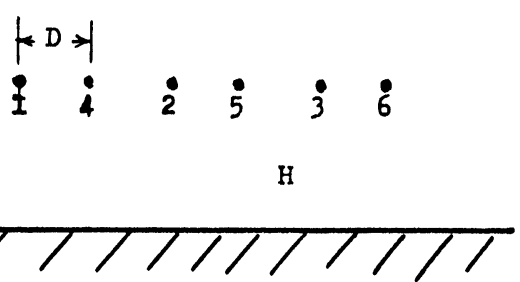

(b) horizontal arrangement

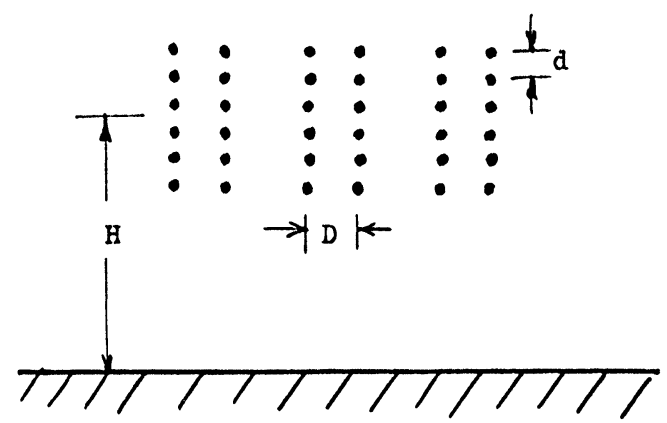

(d) plate arrangement

FIGURE 2 Different arrangements of conductors of new type transmission lines. 
As a check inductance and resistance will be calculated for a typical transmission line ${ }^{7}$ as shown in Fig. 2. Expressions (4) are used for computations of inductance and resistance overhead wires of Fig. 2. The results are compared with that of equations (1) and prove the accuracy of the deduced expressions.

The aim of the present research is the utilization of this mutual effect so that different arrangements of conductors must be studied (see Fig. 2). The conductor heights and spacing between phases may be varied. The results of calculations are drawn in Fig. 3. From this figure it is shown that, mutual inductance between conductors 1 and 3 (Fig. 2a) does not depend upon conductor spacing. This value is also weakly depends upon conductor height; for example, at $\mathrm{H}=8 \mathrm{~m}$, the mutual inductance is $9 \mathrm{mH} / \mathrm{km}$ while at $\mathrm{H}=11 \mathrm{~m}$ it becomes 28 $\mathrm{mH} / \mathrm{km}$. The mutual inductance between conductors 1 and 6 weakly changes with conductor spacinge as the distance between the two circuits is varied from $1 \mathrm{~m}$ to $4 \mathrm{~m}$. The mutual inductance between conductors 1 and 3 at $8 \mathrm{~m}$ height increases from 13 to $18 \mathrm{mH} / \mathrm{km}$ and from 36 to $44 \mathrm{mH} / \mathrm{km}$ at $11 \mathrm{~m}$ height. Calculations prove that the mutual inductance between conductors 1 and 2 is equal to that between 1 and 5 .

The effect of distance between edge conductors for each circuit shows that the rate of rise of the mutual inductance increases as the distance between the two circuits is increased. This will be more efficient if the distance between edge conductors of the upper circuit is decreased as shown in Fig. 3. Therefore, the distance between edge conductors of the upper circuit must be decreased relative to lower one so that the study of potential coefficients, i.e. capacitances of such transmission lines becomes necessary.

The results of the computations of mutual potential coefficients for double circuit transmission lines (Fig. 2a) are shown in Fig. 4. Calculations prove that the mutual capacitance between the two circuits will be increased as the distance between them is decreased. The mutual capacitance between conductors 1 and 6 is reduced due to electric field between conductors 2 and 5. Also, the distance between edge conductors of the upper circuit must be less than that of the lower circuit. This will increase the mutual effect between the two circuits. It can be deduced from Fig. 3 and Fig. 4 that the use of a new earth return path for increasing the mutual effect is more efficient. This means that such a path increases the electric field and thus the mutual capacitance between phases. Therefore, the mutual effect 


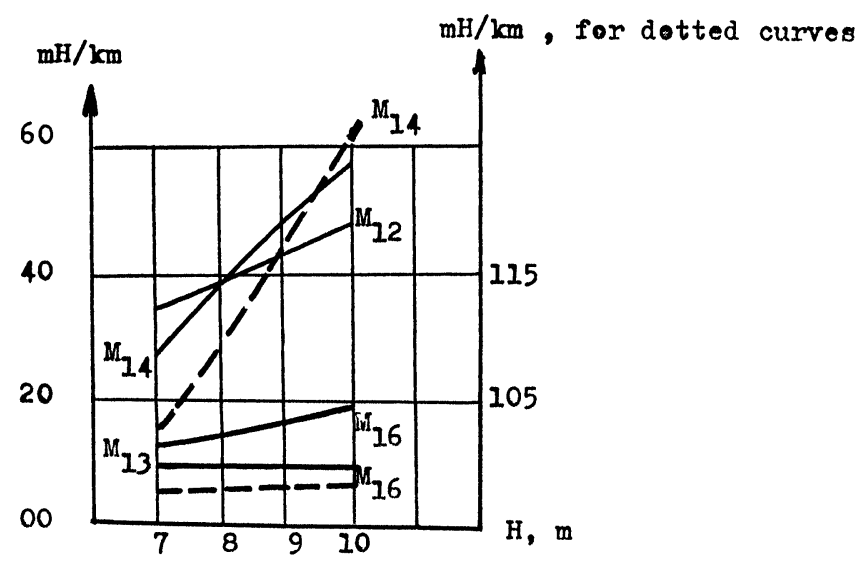

FIGURE 3 The calculated inductances with different heights when the distance between conductors 4 and 6 is $39 \mathrm{~m}$ :

for distance between conductors $1 \& 3=31 \mathrm{~m}$ for $23 \mathrm{~m}$ between conductors $1 \& 3$.

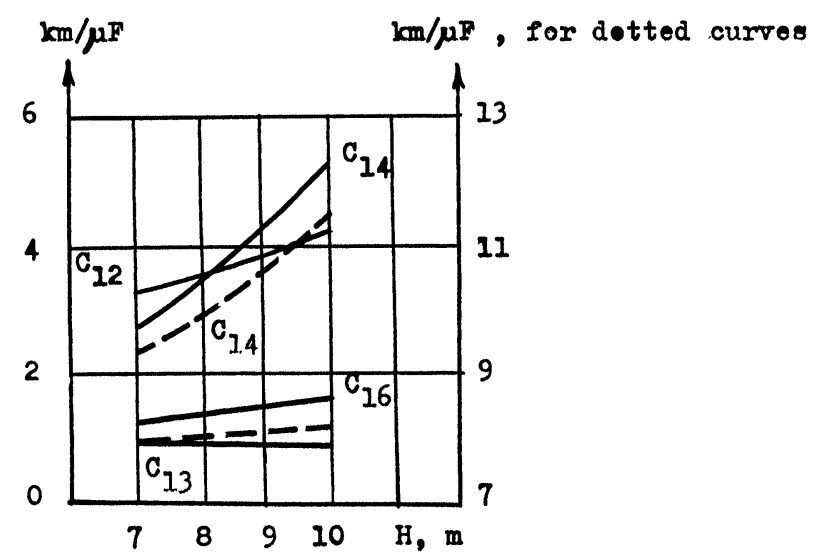

FIGURE 4 The calculated potential coefficients (See Fig. 3).

may be utilized for power transmission from one circuit to another ${ }^{2}$. The conductor arrangement of Fig. 2 a should be changed to that of Fig. $2 b$ and the optimal distance between the two circuits must be realized. This may be done by decreasing the electric field between conductors 2 and 5 . Conductor 2 must be placed above the level of 
conductors 1 and 3 (Fig. 2c). This also decreases the distance between edges of the upper circuit. From this analysis, a new arrangement of conductors will be suggested (see Fig. 2d). This increases the mutual capacitance between the two circuits and may be defined as platetype. This type of transmission lines is selected for the next investigations. For this purpose the physical model of such a line must be erected. Then the steady state performance can be studied.

\section{SIMILARITY CRITERIA OF PLATE TYPE LINES}

Power transmission through UHV transmission lines over long distances (Fig. 5) has a special interest. These lines may be applied if all their electrical performances are investigated. The steady state characteristics must be determined while transient performance and other physical processes can be analysied. Then the application of such lines can be clearified. The modeling of the steady state process is needed, especially if the actual line is not practicable. Simulation of the distributed parameter transmission line has its specific importance - the HF models of transmission lines are a good simple instrument for investigation of steady-state characteristics. For simulation of long distance lines the supply frequency should be increased. The results can be checked by mathematical calculations.

Simulation may be divided into complete and non-complete

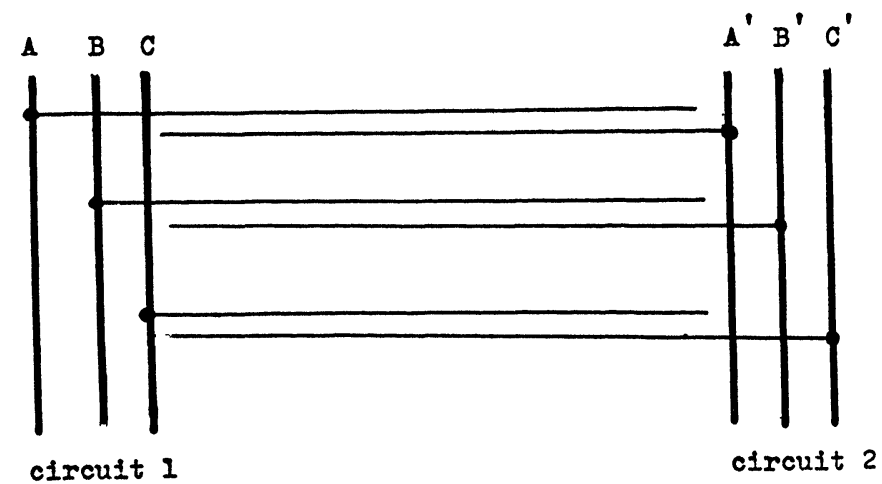

FIGURE 5 The three wire diagram for the proposed transmission line with plate phases. 
modeling. In complete modeling all geometrical dimensions and parameters of the model and actual line should be considered. The scales $\mathrm{m}_{\mathrm{x}}, \mathrm{m}_{\mathrm{y}}$, and $\mathrm{m}_{\mathrm{z}}$ for cartesian coordinates $\mathrm{x}, \mathrm{y}$ and $\mathrm{z}$, respectively, will be related by

$\mathrm{m}_{\mathrm{x}}=\mathrm{m}_{\mathrm{y}}=\mathrm{m}_{\mathrm{z}}$

Equation (6) privents the complete modeling of long distance transmission lines. The line length will be decreased until nonpracticable values of both conductor radius and spacing between phases. Thus:

$\mathrm{m}_{\mathrm{x}} \neq \mathrm{m}_{\mathrm{y}} \neq \mathrm{m}_{\mathrm{z}}$

The similarity criteria of a physical model for long transmission lines must be deduced. The analysis should be based on the mathematical explaination of actual physical processes or on dimensions of the fundamental parameters. There are two methods for the determination of similarity criteria: the first method is defined as the integral analog while the second is the PI-theorem ${ }^{4}$. For the integral analog method, all equations of phenomena should be considered, although for the PI-theorem only the fundamental parameters of the system and simulated process must be obtained.

Using the integral analog method, steady state characteristic of a $500 / 750 \mathrm{kV}, 1000 \mathrm{~km}$ transmission line with plate phases as shown in Fig. 2d should be investigated (see Fig. 5). Voltage V and current I along a section of length $\mathrm{dx}$ may be formulated as

$$
\begin{aligned}
-\mathrm{dV}_{1} / d x & =\left(\mathrm{R}_{1}+\mathrm{j} \omega \mathrm{L}_{1}\right) \mathrm{I}_{1}+\mathrm{j} \omega \mathrm{MI}_{2} \\
-\mathrm{dI}_{1} / \mathrm{dx} & =\left(\mathrm{G}_{1}+\mathrm{j} \omega \mathrm{C}_{1}\right) \mathrm{V}_{1}+(\mathrm{g}+\mathrm{j} \omega \mathrm{K})\left(\mathrm{V}_{1}-\mathrm{V}_{2}\right) \\
-\mathrm{dV}_{2} / \mathrm{dx} & =\left(\mathrm{R}_{2}+\mathrm{j} \omega \mathrm{L}_{2}\right) \mathrm{I}_{2}+\mathrm{j} \omega \mathrm{M} \mathrm{I}_{1} \\
-\mathrm{dI}_{2} / d x & =\left(\mathrm{G}_{2}+\mathrm{j} \omega \mathrm{C}_{2}\right) \mathrm{V}_{2}+(g+j \omega \mathrm{K})\left(V_{2}-V_{1}\right)
\end{aligned}
$$

where 1 and 2 denote the first and second circuits, respectively. The self and mutual capacitances $\mathrm{C}$ and $\mathrm{K}$ as well as self and mutual inductances $L$ and $M$ and self and mutual conductances $G$ and $g$ can be calculated from the geometrical arrangements of phases. The 
current can be assumed as a constant along the length $\mathrm{dx}$. The corona power loss should be neglected. The parameters of both circuits will be assumed the same as $R_{1}=R_{2}=R, L_{1}=L_{2}=L, C_{1}=C_{2}=C$ and $\mathrm{G}_{1}=\mathrm{G}_{2}=\mathrm{G}$.

The first two expressions of equations (8) contain all parameters of the line. Therefore, they may be rewritten after adding the third formula of time as:

$$
\begin{aligned}
-\mathrm{dV}_{1} / \mathrm{dx} & =(\mathrm{R}+\mathrm{j} \omega \mathrm{L}) \mathrm{I}_{1}+\mathrm{j} \omega \mathrm{MI}_{2} \\
-\mathrm{dI}_{1} / \mathrm{dx} & =(\mathrm{G}+\mathrm{j} \omega \mathrm{C}) \mathrm{V}_{1}+(\mathrm{g}+\mathrm{j} \omega \mathrm{K})\left(\mathrm{V}_{1}-\mathrm{V}_{2}\right) \\
\omega \mathrm{t} & =\text { idem }
\end{aligned}
$$

The similarity coefficient $a_{1}$ for the first expression of equations (8) can be obtained as a function of the number of terms of equation $n$ and extra condition coefficient $b_{1}$ as ${ }^{4}$ :

$a_{1}=n-1+b_{1}$

Using this equation, the three coefficients of similarity $a_{1}, a_{2}$ and $a_{3}$ for the three expressions of equations (8) may be determined and are equal to 3,6 , and 1 , respectively. The overall number of similarity criteria is the sum of the three coefficients which is 10 . Hence, similarity criteria of long distance transmission lines with plate phases may be finally defined as

$$
\begin{aligned}
& \mathrm{P}_{1}=\mathrm{V}_{1} / \mathrm{RI}_{1} \mathrm{x}, \quad \mathrm{P}_{2}=\omega \mathrm{L} / \mathrm{R}, \quad \mathrm{P}_{3}=\omega \mathrm{MI}_{2} / \mathrm{RI}_{1} \text {, } \\
& \mathrm{P}_{4}=\mathrm{I}_{1} / \omega \mathrm{CV}_{1} \mathrm{x}, \quad \mathrm{P}_{5}=\mathrm{G} / \omega \mathrm{C}, \quad \mathrm{P}_{6}=\mathrm{g} / \omega \mathrm{C}, \\
& \mathrm{P}_{7}=\mathrm{K} / \mathrm{C}, \quad \mathrm{P}_{8}=\mathrm{gV}_{2} / \omega \mathrm{CV}_{1}, \quad \mathrm{P}_{9}=\mathrm{KV}_{2} / \mathrm{CV}_{1} \text {, } \\
& \mathrm{P}_{10}=\omega \mathrm{t}
\end{aligned}
$$

Using the PI-theorem, these parameters of similarity criteria should be checked. In this case the physical process of steady-state operation may be characterized through all parameters of transmission line. This can be expressed mathematically as follows:

$\mathrm{f}\left(\mathrm{R}, \mathrm{L}, \mathrm{C}, \mathrm{G}, \mathrm{g}, \mathrm{K}, \mathrm{M}, \quad \omega, \mathrm{x}, \mathrm{I}_{1}, \mathrm{I}_{2}, \mathrm{~V}_{1}, \mathrm{~V}_{2}, \mathrm{t}\right)=0$ 
The general number of fundamental parameters is $m=14$. The matrix of dimensions [D] can be formulated as ${ }^{4}$ :

$[D]=\left[\begin{array}{rrrrrrrrrrrrrr}1 & 1 & -3 & -3 & -3 & -3 & 1 & 0 & 1 & 0 & 0 & 2 & 2 & 0 \\ 1 & 1 & -1 & -1 & -1 & -1 & 1 & 0 & 0 & 0 & 0 & 1 & 1 & 0 \\ -3 & -2 & 4 & 3 & 3 & 4 & -2 & -1 & 0 & 0 & 0 & -3 & -3 & 1 \\ -2 & -2 & 2 & 2 & 2 & 2 & -2 & 0 & 0 & 1 & 1 & -1 & -1 & 0\end{array}\right]$

One of the fourth order determinants of matrix (12) will not disappear and contains the dimensions of fundamental parameters. This proves that of the number of independent parameters as well as the number of main units of measurements is equal to $4^{4}$. The parameters of similarity criteria may be calculated by the difference between the quantities of the general number of fundamental parameters $m$ and the numbers of main units $q$. It will be equal to 10 as it was derived also by the integral analog method. Therefore, the main parameters are voltage, resistance, capacitance and angular frequency. The parameters of similarity criteria may be formulated as:

$$
\begin{array}{lll}
\mathrm{P}_{1}^{\prime}=\omega \mathrm{M} / \mathrm{R}, & \mathrm{P}_{2}^{\prime}=\omega \mathrm{L} / \mathrm{R}, & \mathrm{P}_{3}^{\prime}=\mathrm{x} \sqrt{ } \omega \mathrm{RC}, \\
\mathrm{P}_{4}^{\prime}=\mathrm{V}_{2} / \mathrm{V}_{1}, & \mathrm{P}_{5}^{\prime}=\mathrm{G} / \omega \mathrm{C}, & \mathrm{P}_{6}^{\prime}=\mathrm{g} / \omega \mathrm{C}, \\
\mathrm{P}_{7}^{\prime}=\mathrm{K} / \mathrm{C}, & \mathrm{P}_{8}^{\prime}=\mathrm{I}_{2} \sqrt{ } / \mathrm{V}_{1} \sqrt{ } \omega \mathrm{C}, & \mathrm{P}_{9}^{\prime}=\mathrm{I}_{1} \sqrt{ } / \mathrm{V}_{1} \sqrt{ } \omega \mathrm{C}, \\
\mathbf{P}_{10}^{\prime}=\omega \mathrm{t} & &
\end{array}
$$

The parameters $\mathrm{P}_{4}$ and $\mathrm{P}_{7}$ are dimensionless quantities. Hence, the scales of voltage of first and second circuits $m_{v 1}$ and $m_{v 2}$ will be related to scales of self and mutual capacitances $m_{c}$ and $m_{k}$ as follows;

$\mathrm{m}_{\mathrm{v} 2} / \mathrm{m}_{\mathrm{v} 1}=\mathrm{m}_{\mathrm{k}} / \mathrm{m}_{\mathrm{c}}=1$

Equations (13) of the PI-theorem must be compared with equations (10) for the integral analogue method. The relation between both results can be simplified in the form: 


$$
\begin{array}{lll}
\mathrm{P}_{1}=1 / \mathrm{P}_{3}^{\prime} \mathrm{P}_{9}^{\prime}, & \mathrm{P}_{2}=\mathrm{P}_{2}^{\prime}, & \mathrm{P}_{3}=\mathrm{P}_{1}^{\prime} \mathrm{P}_{8}^{\prime} / \mathrm{P}_{9}^{\prime} \\
\mathrm{P}_{4}=\mathrm{P}_{9}^{\prime} / \mathrm{P}_{3}^{\prime}, & \mathrm{P}_{5}=\mathrm{P}_{5}^{\prime}, & \mathrm{P}_{6}=\mathrm{P}_{6}^{\prime}, \\
\mathrm{P}_{7}=\mathrm{P}_{7}^{\prime}, & \mathrm{P}_{8}=\mathrm{P}_{4}^{\prime} \mathrm{P}_{6}^{\prime}, & \mathrm{P}_{9}=\mathrm{P}_{4}^{\prime} \mathrm{P}_{7}^{\prime} \\
\mathrm{P}_{10}=\mathrm{P}_{10}^{\prime} & &
\end{array}
$$

This check means that both methods give the same parameters of similarity criteria. Therefore, the integral analogue method is recommended for such simulation.

\section{THE INDEPENDENT PARAMETERS}

The coefficients of similarity are equal to 4 , and all parameters of the physical model can be expressed through these four coefficients. They should be defined as independent parameters. The scales of these four independent parameters will be selected for the simulation of the proposed long distance transmission with plate phases. The selection should be based on the practicability of the measured values in laboratory. Firstly, the scale of frequency $m_{f}$ will be assumed. The operating frequency is suggested as $5 \mathrm{MHz}$ so that the scale of frequency becomes $10^{-5}$ and the length of EHF physical model may be deduced. The length scale $m_{1}$ should be related to scale of angular frequency $\mathrm{m}_{\omega}$. In this case, the frequency criteria $(\omega \mathrm{t}=\mathrm{idem})$ will be achieved. The scale of length may be formulated as a function of scales of resistance and inductance or capacitance $\left(m_{r}\right.$ and $m_{L}$ or $\left.m_{c}\right)$ as

$\mathrm{m}_{1}=1 / \sqrt{ } \mathrm{m}_{\mathrm{r}} \mathrm{m}_{\mathrm{c}} \mathrm{m}_{\omega}=1 / \mathrm{m}_{\omega} \sqrt{ } \mathrm{m}_{\mathrm{L}} \mathrm{m}_{\mathrm{c}}$

The EHF model will have a length of $10 \mathrm{~m}$ while the scale of wave velocity $\mathrm{m}^{\prime \prime}$ can be expressed by

$\mathrm{m}^{\prime \prime}=1 / \sqrt{ } \mathrm{m}_{\mathrm{L}} \mathrm{m}_{\mathrm{c}}$

It is known that the propagation velocity on overhead type of lines is very closed to light velocity ${ }^{7}$. The scale of length may be related to the scale of time $m_{t}$ as $m_{1}=m_{t}$. The other three scales must be 
selected according to the practicability application of EHF physical model.

\section{CONCLUSIONS}

The deduced expressions for frequency dependent parameters of transmission lines reduce the computational time with the same accuracy. The mutual effect between conductors and between circuits of double circuit lines can be utilized. The proposed new earth path increases the electric field between phases. The distance between edge conductors of upper circuit of transmission line should be shorter than that of lower one.

The obtained arrangement of conductors (plate phases) gives the maximum transmitted power for long transmissions. The determined parameters of similarity criteria for plate lines can be used successfully. This line can be simulated by EHF physical models.

For modeling of long distance lines, the integral analog method is recommended. The suggested EHF model is practicable for steady state investigation.

\section{REFERENCES}

1. M. Hamed and R.S. Momtaz (1984): The electrical performance of the controlled type transmission lines. Proc. of 9 th inter. con. for statistics \& computer science, Cairo, pp. 269-277.

2. M. Hamed and S.S. El-dessouky (1984): Coaxial overhead transmission line performance. Journal of The Egyptian Society of Engineers, Cairo, vol. 23, No. 1.

3. M.L. Paris et al (1980): Round table on UHV transmission feasibility a decate 10 years after the studies carried out by the CIGRE UHV AD HOC Group, Electra, No. 73, pp. 17-33.

4. V.A. Venikov (1976): Theory of simulation and modelling. Book, Moscow, High School.

5. J.R. Carson (1926): Wave propagation inoverhead wires with ground return. Bell Sys. Tech. J., vol. 5, pp. 539-554.

6. M. Hamed (1983): On the possibility of transient calculations in single circuit untransposed transmission lines using Laplace transforms. JIEEEC, Amman, vol. 1, pp. 39-43.

7. M.M. Ahmed (1980): Overvoltage analysis in new type transmission lines. TSS J., Cairo, pp. 52-66. 

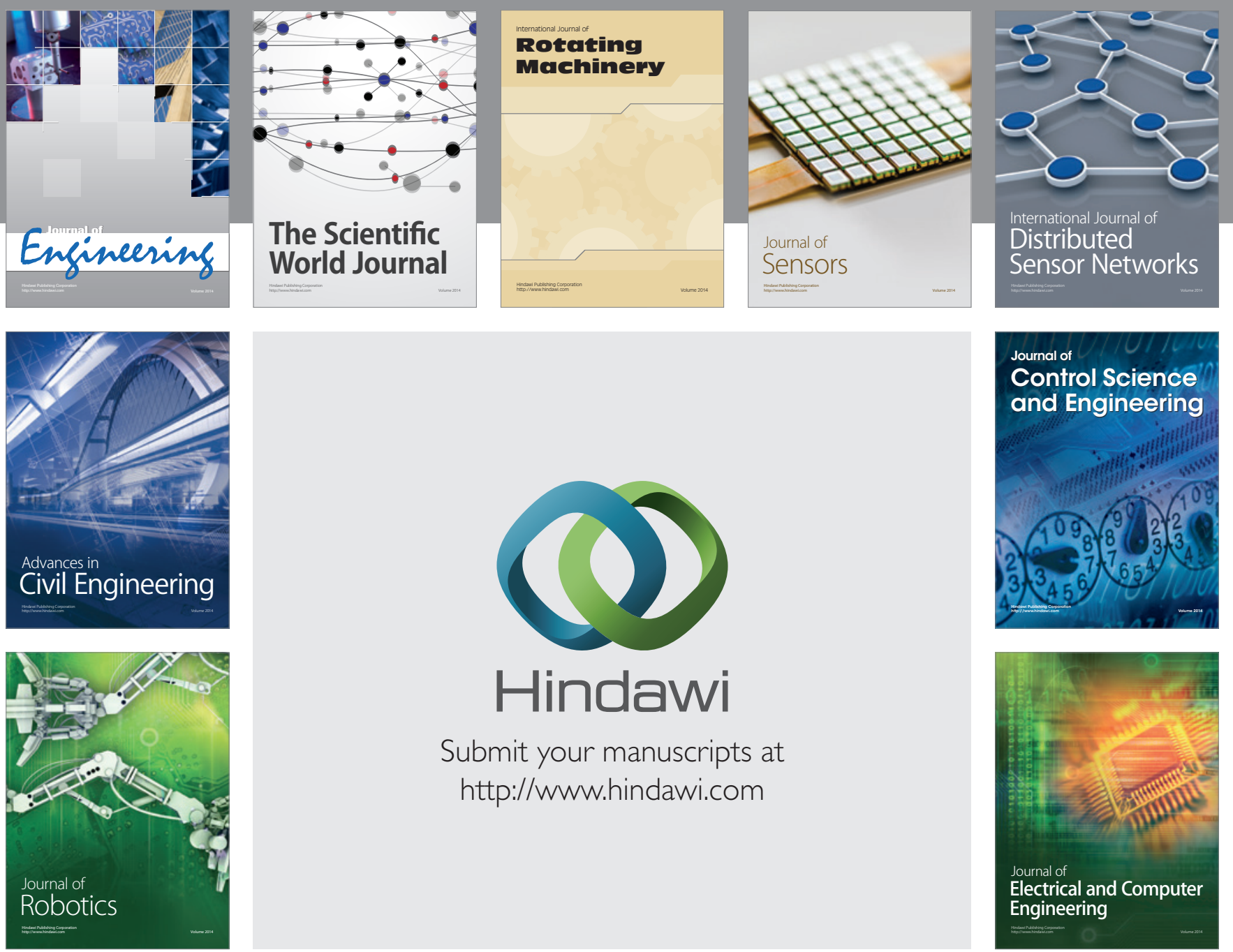

Submit your manuscripts at

http://www.hindawi.com
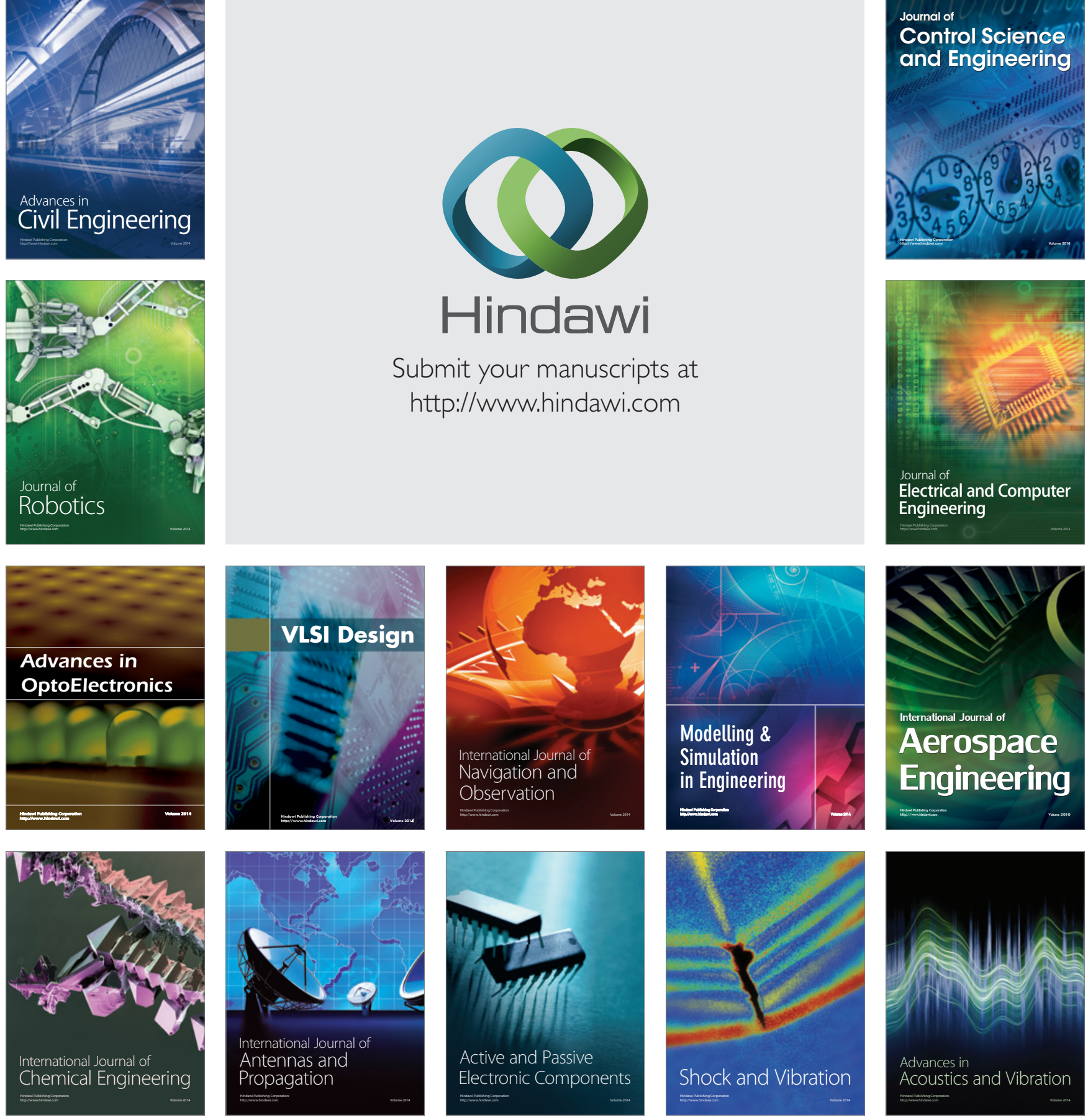